\title{
HISTOLOGIA DA INTERAÇÃO Colletotrichum guaranicola E Paullinia cupana var. sorbilis EM CLOONES RESISTENTE E SUSCETIVEL
}

\author{
JÂNIA L.S. BENTES ${ }^{1^{* *}}$ \& KYIOSHI MATSUOKA ${ }^{1}$
}

${ }^{1}$ Departamento de Fitopatologia, Universidade Federal de Viçosa, MG, CEP 36570-000, e-mail: matsuoka@mail.ufv.br

(Aceito para publicação em 08/10/2001)

Autor para correspondência: Kiyoshi Matsuoka

BENTES, J.L.S. \& MATSUOKA, K. Histologia da interação Colletotrichum guaranicola e Paullinia cupana var. sorbilis em clones resistente e suscetível. Fitopatologia Brasileira 27:071-077. 2002.

\section{RESUMO}

Foi estudado o processo de infecção de Colletotrichum guaranicola em clones de guaranazeiro (Paullinia cupana var. sorbilis) resistente e suscetível, por meio de microscopia de luz. Avaliaram-se quantitativamente os eventos de pré-penetração em folhas novas e velhas dos clones. Observou-se diferença quantitativa quanto à formação de apressório em folhas novas e velhas dos clones, sendo maior em folhas novas do clone suscetível. Estruturas de pré-penetração e infecção foram semelhantes nos dois clones. O processo de infecção teve inicio após a germinação do fungo e formação de apressório na superfície do hospedeiro, seguido de penetração direta da cutícula e da parede celular das células epidérmicas. Dentro da célula, a hifa de infecção deu origem a uma vesícula, que em seguida formou a hifa primária que se ramificou, originando a hifa secundária, que colonizou intra e intercelularmente a epiderme e o parênquima, causando desorganização dos tecidos e necrose. Observou-se uma diferença temporal na colonização dos tecidos dos clones. No clone suscetível, com $48 \mathrm{~h}$ após a inoculação, as células da epiderme e do parênquima estavam colonizadas por hifas intra e intercelulares. No quinto dia após a inoculação, observou-se o surgimento dos sintomas. No clone resistente, a colonização só foi observada no quarto dia após a inoculação. Somente no sétimo dia após a inoculação, foram observados os primeiros sintomas típicos da doença.

Palavras-chave adicionais: antracnose, infecção, resistência.

\section{ABSTRACT \\ Histology of Colletotrichum guaranicola and Paullinia cupana var. sorbilis on resistant and susceptible clones}

The pre-penetration and infection processes of Colletotrichum guaranicola on resistant and susceptible clones of Paullinia cupana var. sorbilis were studied by light microscopy. The percentage of germination of conidia on young leaves was higher than on old leaves, although no difference was found between resistant and susceptible clones. Quantitative differences were observed in the appressorium formation on susceptible and resistant leaf surfaces. More appressoria were found on susceptible than on resistant leaves $24 \mathrm{~h}$ after inoculation. The morphology of pre-penetration and infection structures was similar for both clones: direct penetration, with infection hyphae and vesicles present in the epidermal cells; development of primary and secondary hyphae; inter and intracellular colonization of the parenchyma. However, events such as parenchyma colonization and onset of leaf symptoms took 48-hours longer to unfold in resistant leaves than in susceptible leaves.

\section{INTRODUÇÃO}

O Brasil é o único produtor de guaraná [Paulinia cupana var. sorbilis (Mart.) Ducke], em escala comercial, no mundo (Guaraná, 1985). Segundo estimativas, em 1999, as plantações de guaraná no país ocupavam aproximadamente 14.094 ha dos quais 7.756 ha encontravam-se no Estado do Amazonas (IBGE, 1999), portanto, o guaraná é de grande valor para a economia regional, pois alcança bons preços na comercialização e constitui-se numa alternativa para diversificação da agricultura.

Um fator que limita a produção e a expansão da guaranicultura no Amazonas é a antracnose, causada pelo

\footnotetext{
* Parte da Tese de Mestrado do primeiro autor. Universidade Federal de Viçosa (1999).

** Bolsista do CNPq.
}

fungo Colletotrichum guaranicola Albuq. considerada a doença mais séria da cultura. Visando o controle mais eficiente desta doença, pesquisadores da Embrapa Amazônia Ocidental têm recomendado o uso de clones resistentes. Porém, os mecanismos envolvidos na resistência destes clones são desconhecidos

Estudos relacionados com a interação Colletotrichum spp.-hospedeiros são comuns na literatura, mas pouco se sabe sobre o patossistema C. guaranicola e guaranazeiro. Diante da necessidade de maiores informações sobre esta interação, o presente trabalho teve como objetivos: estudar o processo de infecção no patossistema; observar as modificações morfológicas e citológicas decorrentes desta interação em clones de guaranazeiro resistente e suscetível à antracnose; e quantificar os eventos de pré-penetração, comparando os dois genótipos em estudo. 


\section{MATERIAL E MÉTODOS}

\section{Seleção dos clones e isolado do patógeno}

Sete clones de guaranazeiro $(224,368,514,619,620$, 626 e 628) apresentando diferentes níveis de resistência, foram inoculados com três isolados de C. guaranicola, obtidos de plantas infetadas, de três distintas regiões produtoras de guaraná (Iso 1- Itacoatiara-AM, Iso 2- Manaus-AM e Iso FMato Grosso-MT). A inoculação foi feita em mudas, na casa de vegetação, usando-se discos de cultura pura, com dez dias de idade e com $5 \mathrm{~mm}$ de diâmetro, contendo micélio e conídios do patógeno. Foram usados três discos por folha, depositados em ferimentos, feitos com agulha sem atravessar o tecido foliar, na face adaxial das três últimas folhas do ramo principal, enumeradas de um a três a partir do topo. Após a inoculação, as plantas permaneceram em câmara úmida por $48 \mathrm{~h}$, e em seguida foram mantidas em casa de vegetação até a avaliação dos sintomas.

Adotou-se o delineamento experimental inteiramente casualizado, com três repetições, cada repetição constituindose de uma planta. A testemunha constou de plantas que receberam discos de meio de cultura sem o patógeno. Sete dias após a inoculação, foi feita a avaliação através da medição com régua, do diâmetro das lesões, tomando-se as medidas vertical e horizontal. O ensaio foi repetido duas vezes.

\section{Estudo do processo de infecção}

Um clone resistente e um suscetível selecionados foram inoculados com o isolado do fungo também selecionado no ensaio descrito anteriormente.

$O$ fungo foi cultivado em placas de Petri contendo meio BDA, mantidas sob luz fluorescente constante e à temperatura ambiente. Culturas com dez dias de idade foram utilizadas para o preparo do inóculo.

Trinta dias antes da inoculação, as mudas dos clones selecionados, foram podadas para obtenção de folhas com estádio fenológico conhecido. Nove grupos de três plantas foram preparados para a inoculação.

As mudas foram inoculadas com suspensão de $10^{5}$ conídios/ml, por atomização na face adaxial das folhas com DeVilbis $\mathrm{n}^{\circ} 15$, sem ferimentos. Após a inoculação, as plantas permaneceram em câmara úmida por 48 h. Em seguida, as mudas foram mantidas em casa de vegetação, até o término da coleta das amostras, que foi efetuada em cada grupo de plantas, às $6,12,24,48,72,96,120,144 \mathrm{e}$ $168 \mathrm{~h}$ após a inoculação. As amostras consistiram das folhas novas e velhas de cada clone. A idade das folhas foi determinada de acordo com as características descritas por Nascimento Filho e Moreira (dados não publicados) onde, estádio 1 corresponde à folha reta, estádio 2 à folha marrom, estádio 3 à folha verde clara e estádio 4 folha verde escura. Foram consideradas folhas novas aquelas com características de 1 a 3 e folhas velhas aquelas em estádio fenológico 4 .

As folhas coletadas foram cortadas em fragmentos de $0,5 \mathrm{~cm}^{2}$. Parte destes fragmentos foram clareados, de acordo com o método descrito por Longo et al. (1994), em cloral hidratado (250 g/100 $\mathrm{ml}$ de água destilada) durante cinco dias, seguido de três lavagens em água destilada. A outra parte das amostras foi fixada em FAA (formaldeido $35 \%$ - 10ml, álcool etílico 95\% - 50ml, ácido acético glacial - 5ml, água destilada - $35 \mathrm{ml}$ (SASS, 1958).

Quantificação dos eventos de pré-penetração em folhas novas e velhas clareadas de clone resistente e suscetível

As amostras avaliadas foram coletadas nos períodos de 6 a 48 h após a inoculação, clareadas e coloridas com azul de algodão + lactofenol (100 ml de lactofenol, $1 \mathrm{ml} \mathrm{de}$ azul de algodão aquoso 1\%, $20 \mathrm{ml}$ de ácido glacial acético) (Byrne et al., 1997; Munaut \& Maraite, 1998). Os conídios presentes nas amostras foram avaliados quanto à germinação e à formação de apressório. Para cada intervalo de coleta, foram avaliados 300 conídios, observados ao microscópio de luz.

\section{Observação da colonização dos tecidos}

Foram usadas as amostras coletadas às 24, 48, 72, 94120 e $168 \mathrm{~h}$ após a inoculação que foram fixadas em FAA, incluídas em resina SPURR e seccionadas a uma espessura de $1 \mu \mathrm{m}$ usando-se ultramicrótomo marca SORVALL MT2-B, equipado com navalha de vidro. Os cortes foram coloridos com azul de toluidina $\mathrm{O}$ 0,1\% (borax p.a. $0,1 \mathrm{~g}$; toluidina $\mathrm{O} 0,1 \mathrm{~g} ; 100 \mathrm{ml}$ de água destilada) e observados ao microscópio de luz.

\section{RESULTADOS}

\section{Seleção de clones e isolado}

Os três isolados testados infetaram diferentes clones, e apresentaram variação quanto à patogenicidade (Tabela 1).

Os isolados não diferiram em sua virulência quando inoculados nos clones 368, 626 e 514. Para o clone 620, os isolados ISO-1 e ISO-F foram os mais virulentos, tendo apresentado o maior diâmetro de lesões observado. Para os clones 224 e 619 , o isolado ISO-F foi o mais virulento, diferindo estatisticamente dos demais. $\mathrm{Na}$ testemunha não houve o desenvolvimento de lesões.

Diante destes resultados, os clones selecionados foram 626 , como resistente, e 368 , como suscetível, devido à maior disponibilidade de mudas deste clone no viveiro. Como não houve diferença significativa entre os isolados quando inoculados nos clones 368 e 626, optou-se pelo uso do isolado ISO-1, por apresentar maior produção de esporos que os demais isolados avaliados, quando exposto à luz constante, o que é desejável para a produção de inóculo.

\section{Avaliação dos eventos de pré-penetração em folhas novas e velhas dos clones resistente e suscetível}

No período de $6 \mathrm{~h}$ após a inoculação (h.a.i), não foi observada germinação dos conídos nos dois clones. No período ente 6 e 12 h.a.i., observou-se que a germinação havia iniciado, e foi significativamente maior (Tukey 5\%) em folhas novas do clone suscetível, atingindo o máximo 
Tabela 1 - Diâmetro de lesões causadas por isolados de Colletotricum guaranicola em diferentes clones de guaranazeiro (Paullinia cupana var. sorbilis)

\begin{tabular}{cccc}
\hline \multirow{2}{*}{ Clone } & \multicolumn{3}{c}{ Diâmetro de lesões* } \\
\cline { 2 - 4 } & ISO-1 & ISO-2 & ISO-F \\
\hline 368 & $2,8^{\mathrm{A}}$ & $2,9^{\mathrm{A}}$ & $1,5^{\mathrm{A}}$ \\
620 & $5,3^{\mathrm{A}}$ & $1,5^{\mathrm{AB}}$ & $3,3^{\mathrm{B}}$ \\
628 & $0^{\mathrm{B}}$ & $2,6^{\mathrm{A}}$ & $1,6^{\mathrm{AB}}$ \\
224 & $0^{\mathrm{B}}$ & $0^{\mathrm{B}}$ & $2,7^{\mathrm{A}}$ \\
619 & $0^{\mathrm{B}}$ & $0,7^{\mathrm{B}}$ & $2,5^{\mathrm{A}}$ \\
514 & $0^{\mathrm{A}}$ & $0^{\mathrm{A}}$ & $0,8^{\mathrm{A}}$ \\
626 & $0^{\mathrm{A}}$ & $0^{\mathrm{A}}$ & $0^{\mathrm{A}}$ \\
\hline
\end{tabular}

Teste de Tukey $5 \%$.

Valores $=$ diâmetro das lesões em $\mathrm{cm}$. Valores seguidos da mesma letra não diferiram estatisticamente

de germinação observado $(94,7 \%)$ no período de 24 h.a.i. (Figura 1A).

$\mathrm{O}$ clone resistente não mostrou diferença quanto à germinação de conídios entre folhas novas ( $88,7 \%$ ) e velhas ( $85 \%$ ), no período de 48 h.a.i. (Tukey 5\%) (Figura 1 B).

A formação de apressório foi significativamente maior em folhas novas, tanto para o clone suscetível quanto para o resistente, com o máximo ( $94 \%$ ), observado em folhas novas do clone suscetível no período de 24 h.a.i, (Tukey $5 \%$ ), (Figuras $2 \mathrm{~A}$ e B).

\section{Processo de infecção e colonização dos tecidos}

Os conídios germinam através de um tubo germinativo, que deu origem, na maioria dos casos, a um apressório globoso, de coloração marron-escuro (Figura 3 A).

No apressório encontrou-se o cone apressorial (Figura 3 B), através do qual o fungo emitiu uma hifa de infecção para o interior da célula (Figura $3 \mathrm{C}$ ), que atravessou a cutícula e a parede celular de células da epiderme. Após penetrar na parede celular, a hifa de infecção deu origem a uma vesícula de infeção e hifa primária (Figura 3 D), que se formou na célula epidérmica.

A hifa primária cresceu na célula inicialmente infetada e passou a colonizar células adjacentes da epiderme (Figura 3 E). Em seguida, ramificou-se para colonizar inter e intracelularmente o parênquima (Figuras $3 \mathrm{~F} \mathrm{e} \mathrm{G}$ ), que mais tarde foi totalmente tomado pelas hifas (Figura $3 \mathrm{H}$ ), surgindo então áreas necróticas no tecido colonizado. A colonização prosseguiu pelo tecido foliar, através da ramificação das hifas, que colonizaram as células adjacentes, ampliando assim a área necrosada e causando os sintomas típicos da doença.

Tanto no clone resistente quanto no suscetível, foram encontradas modificações na parede celular nas células da epiderme (Figuras $4 \mathrm{~A}, \mathrm{~B} \mathrm{e} \mathrm{C}$ ), que foram vistas ao microscópio como modificações de parede celular, que se formou na região abaixo do apressório, no sítio de penetração.
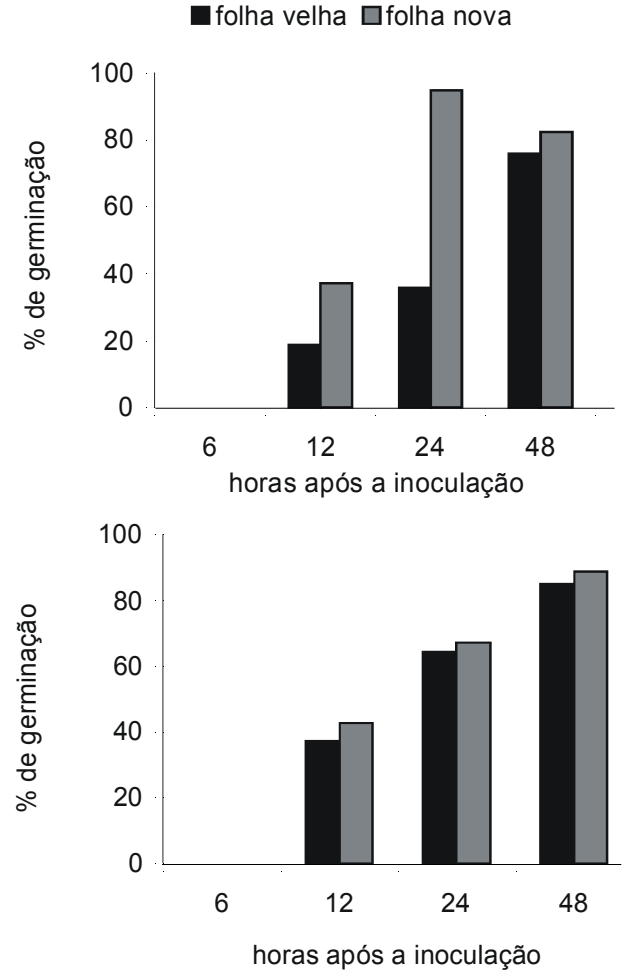

FIG. 1 - Porcentagem de germinação de conídios em clones de guaranazeiro (Paullinia cupana var. sorbilis) suscetível (A) e resistente (B) a Colletotrichum guaranicola em folhas novas e velhas.

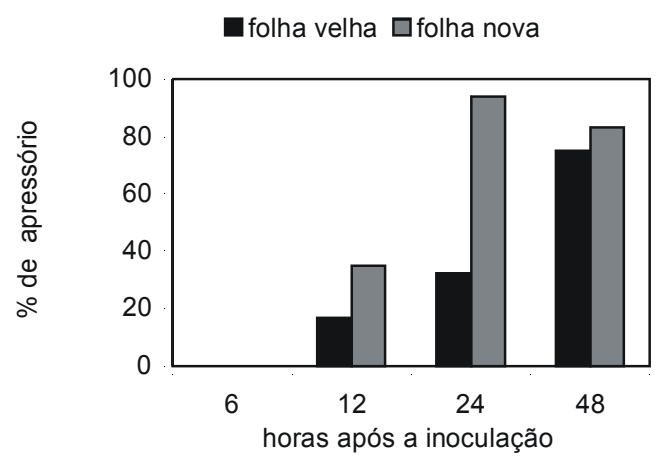

B

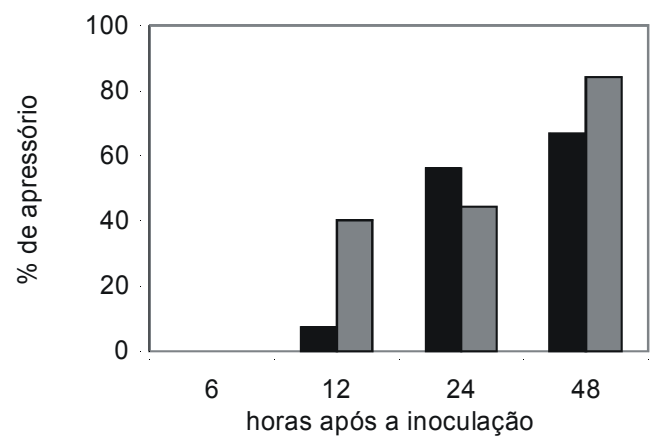

FIG. 2 - Porcentagem de formação de apressório em clones de guaranazeiro (Paullinia cupana var. sorbilis) (A) suscetível e (B) resistente a Colletotrichum guaranicola em folhas novas e velhas. 

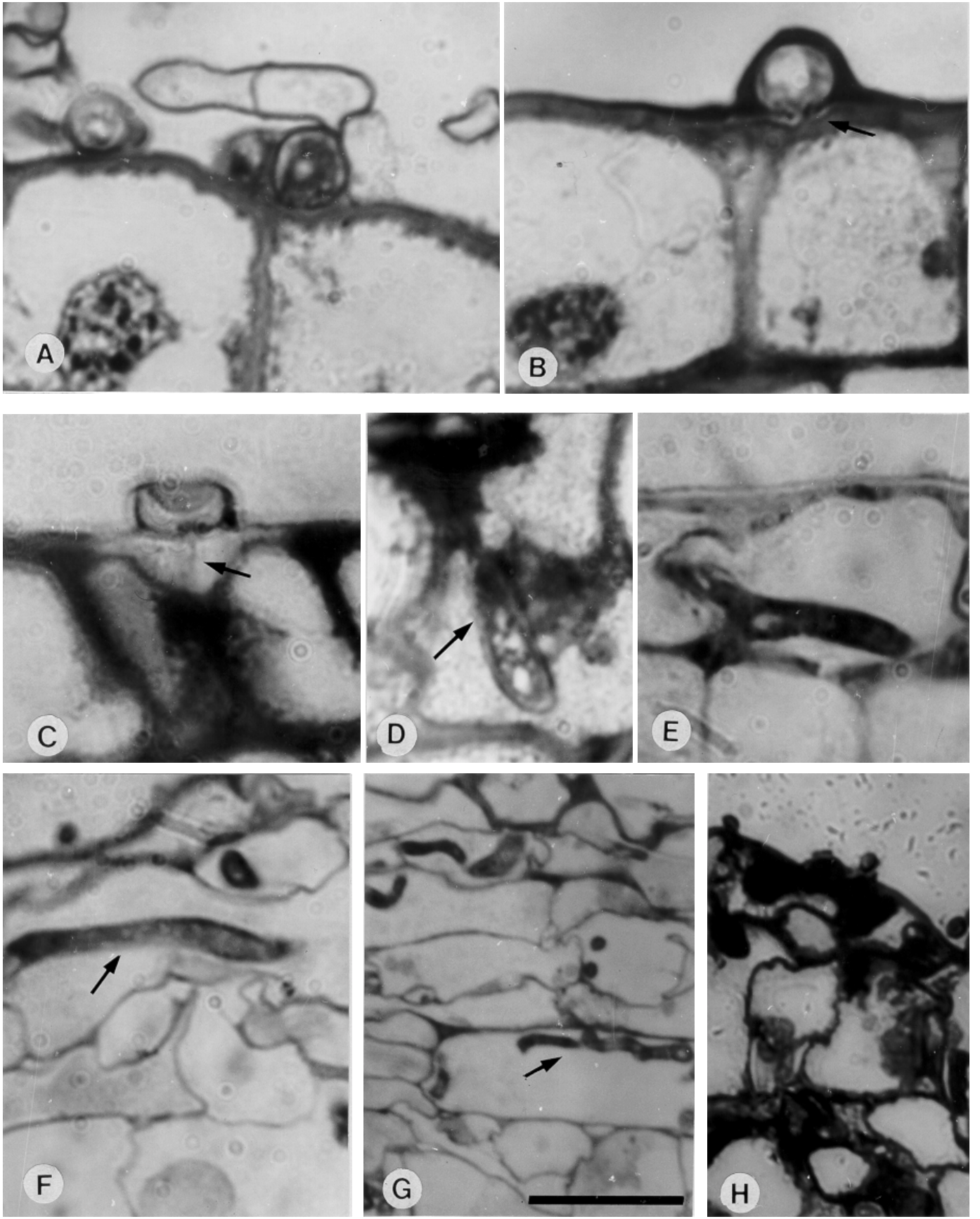

FIG. 3 - Processo de infecção de Colletotrichum guaranicola em guaranazeiro (Paullinia cupana var. sorbilis). A) Conídio germinado com apressório na superfície do hospedeiro. B) Apressório com cone apressorial (seta); C) Hifa de infecção penetrando (seta); D) Hifa primária em célula epidérmica; E) Hifa ramificando em célula epidérmica; F e G) Colonização de células epidérmicas e do parênquima (setas); $H$ ) Tecido colonizado e necrosado (Barra em A, B, C, D, E, F $=10 \mu \mathrm{m}$, em G e H $=25 \mu \mathrm{m}$ ).

Penetração e colonização de tecidos em clone suscetível

Com 24 h.a.i., a penetração nas células da epiderme havia ocorrido, podendo-se observar a presença de apressório exibindo cone apressorial, e de vesícula de infecção com hifa primária assim como hifas que haviam ramificado e invadido o interior de células. Com 48 h.a.i., as células do parênquima estavam colonizadas. No terceiro e quarto dias após a inoculação, as células da epiderme e do parênquima estavam totalmente colonizadas por hifas intra e intercelulares. No quinto dia, surgiram os primeiros sintomas necróticos, devido à destruição e morte das células infetadas.

Penetração e colonização de tecidos em clone resistente A penetração ocorreu 48 h.a.i. e observou-se a pre- 


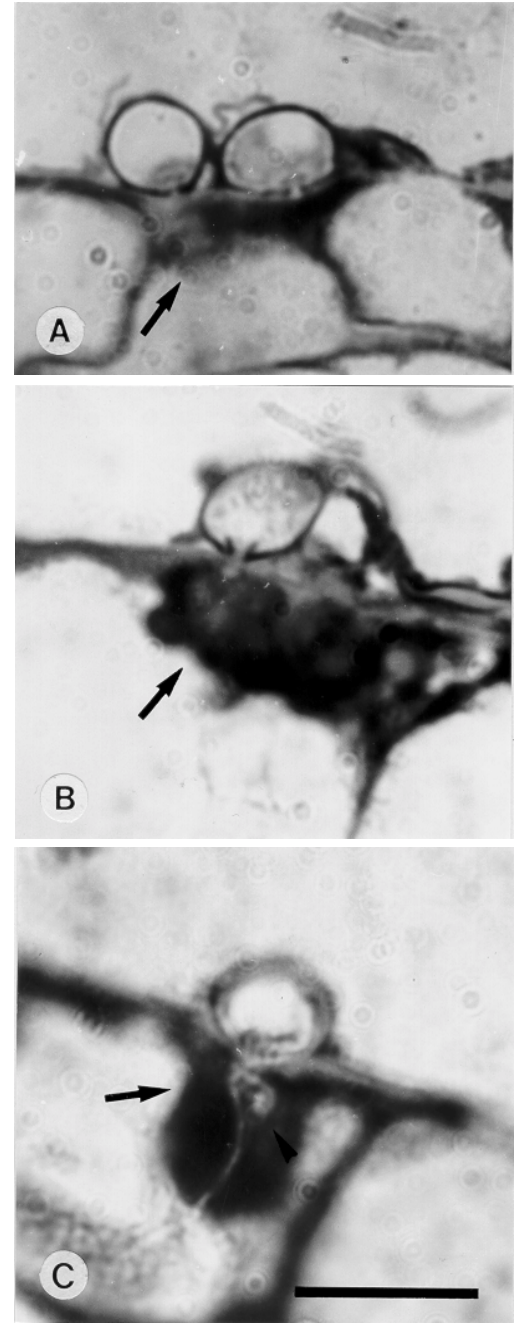

FIG. 4 - Formação de papila (seta) em material resistente de guarnazeiro (Paullinia cupana var. sorbilis) (A, B) restringindo a penetração do Colletotrichum guaranicola, e suscetível (C) aparentemente a hifa de infecção atravessa a papila $($ Barra $=10 \mu \mathrm{m})$.

sença de vesícula de infecção com hifa primária na célula inicialmente infetada. Neste período, não foram encontradas hifas em outras células da epiderme ou do parênquima. No terceiro dia após a inoculação, algumas hifas estavam presentes em células da epiderme, e no quarto dia após a inoculação, o parênquima apresentava hifas intra e intercelulares, que se ramificavam e colonizavam as células adjacentes. No quinto dia, todas a camadas de células estavam tomadas por hifas intra e intercelulares, porém somente no sétimo dia após a inoculação é que se observou o surgimento de sintomas necróticos no tecido, com células totalmente destruídas.

\section{DISCUSSÃO}

Colletotrichum guaranicola apresentou variação na patogenicidade, conforme o genótipo do hospedeiro.
Segundo Dodd et al. (1992) e Waller (1992), a patogenicidade de isolados de fungos fitopatogênicos está relacionada com fatores do ambiente, com o genótipo do hospedeiro.

Durante o ensaio de seleção dos clones e do isolado, não se observou qualquer sintoma da doença no clone 626 quando inoculado com os isolados em estudo. Porém, nas inoculações seguintes este apresentou sintomas semelhantes aos observados no clone suscetível. Entretanto, no suscetível os sintomas foram observados cinco dias após a inoculação, enquanto no resistente os sintomas só começaram a surgir a partir do sétimo dia após a inoculação. No clone 626 não se observa sintomas da antracnose em campos de produção, segundo informação pessoal (pesquisador José Firmino da Embrapa Amazônia Ocidental). Porém, no presente trabalho este material apresentou os sintomas da doença quando foi inoculado em casa de vegetação. Tal comportamento pode ser atribuído à idade das folhas inoculadas, visto que o desenvolvimento das lesões está relacionado com a idade dos tecidos afetados, sendo as folhas mais novas, mais suscetíveis (Batista, 1983; Duarte et al., 1995). No ensaio de seleção do material, as mudas utilizadas apresentavam folhas velhas em sua maioria, as quais não manifestaram sintomas. Já nas inoculações seguintes, as mudas haviam passado por uma poda, e as inoculações foram feitas após o rebrotamento, em folhas mais novas que aquelas utilizadas anteriormente, o que pode ter favorecido o desenvolvimento dos sintomas em folhas novas, já que folhas velhas não desenvolveram sintomas até sete dias após a inoculação, quando foi feita a última coleta das amostras. $O$ fato de que em condições de campo as plantas apresentam folhas totalmente desenvolvidas em sua maioria e aliado às condições adversas do meio ambiente no campo, o que não ocorre em inoculações em condições controladas como temperatura e umidade, pode também estar relacionado com a não observação de sintomas no campo, e sim em casa de vegetação.

A germinação dos conídios ocorreu entre 6 a $12 \mathrm{~h}$ após a inoculação, independente do genótipo do hospedeiro ou da idade da folha.

Pela avaliação dos eventos de pré-penetração em folhas de idades diferentes, a porcentagem de germinação não diferiu entre folhas novas e velhas no clone resistente, porém, no clone suscetível a germinação foi maior em folhas novas. A formação de apressório, foi maior em folhas novas de ambos os clones, mostrando que há diferença nos eventos de pré-penetração conforme a idade dos tecidos, sendo mais evidente quanto à formação de apressório. Segundo Esquerré-Tugaýe et al. (1992), nem todas as partes das plantas são igualmente suscetíveis a espécies de Colletotrichum, e muitas vezes a resistência de órgãos resulta de uma falha do fungo em penetrar os tecidos.

A menor porcentagem de germinação e formação de apressórios em folhas velhas pode estar relacionada com a composição da cutícula das folhas (Pascholati \& Leite, 1995), às mudanças na topografia das folhas velhas ou à composição química da superfície foliar, que segundo Baylei et al. (1992), existem evidências de que a natureza química 
da superfície do hospedeiro pode influenciar na formação de apressório. Manandhar et al. (1995), em um estudo sobre o desenvolvimento de C. gloeosporioides em frutos de pimentão (Capsicum annuum L.), observaram que em frutos que tiveram a camada de cera cuticular removida, através de tratamento com clorofórmio, apresentaram abundante formação de apressório. Mercure et al. (1994), estudando o processo de infecção de C. graminicola em folhas de milho (Zea mays L.), observaram que as folhas mais novas apresentavam maior porcentagem de conídios aderidos que as mais velhas. Segundo estes autores, esta diferença depende não somente do conídio mas também de mudanças na topografia da superfície do hospedeiro, devido à deposição de cera, o que altera a sinalização topográfica necessária para a diferenciação das estruturas do fungo. Os autores sugerem ainda que, estes resultados influenciam diretamente no desenvolvimento da doença, pois uma rápida aderência dos conídios na superfície do hospedeiro aumenta a chance de sucesso no estabelecimento do patógeno.

O apressório de C. guaranicola apresenta uma estrutura chamada de cone apressorial, com forma de funil. Skipp et al. (1995) citam que, o cone apressorial é composto de material de parede fúngica e que se forma junto ao poro germinativo. A função do cone ainda não está bem esclarecida, mas acredita-se que atue como foco de pressão hidrostática que impulsiona a hifa de infecção para o interior da célula epidérmica do hospedeiro (Bayley et al., 1992).

No presente trabalho foi observado que após a penetração, o fungo desenvolveu uma vesícula e a partir desta, surgiu uma hifa primária, que colonizou a célula inicialmente infetada e as células adjacentes, causando a desorganização do protoplasma celular e a morte das células infetadas, onde o fungo continuou a se desenvolver. Processos semelhantes foram descritos nos patossistemas C. truncatun (Schwein) Andrus \& W.D. Moore e Pisum sativum L. (O'Conell et al., 1993) e C. sublineolum Henn. in Kab. \& Bubák e sorgo [Sorghum bicolor (L.) Moench] (Wharton \& Julian, 1996).

Comparando-se o clone suscetível com o resistente, observou-se que o desenvolvimento do fungo ocorreu da mesma maneira em ambos, apesar de haver uma diferença temporal nos eventos de penetração e colonização dos tecidos nestes clones. No clone suscetível, após 24 h da inoculação, foi possível observar a colonização de células da epiderme, enquanto no resistente esta colonização só foi vista no terceiro dia após a inoculação. Esta diferença refletiu no surgimento dos sintomas, pois no clone suscetível os sintomas surgiram cinco dias após a inoculação, enquanto que no resistente somente sete dias após a inoculação. A diferença na penetração e colonização observada com 24 h.a.i. pode estar relacionada à maior porcentagem de formação de apressórios no clone suscetível neste período. Em vista da maior quantidade de apressório, houve maior penetração e conseqüente colonização de tecidos neste material.

Em algumas células, observou-se a formação de papilas, tanto no clone resistente quanto no suscetível. A formação de papilas é encontrada naquelas células que estão em estreito contato com o patógeno, e são formadas em resposta à infecção em plantas resistentes e suscetíveis, visando evitar o estabelecimento do patógeno em seus tecidos (Esquerré-Tugayé et al., 1992). Porém, nem sempre as papilas são efetivas em restringir a penetração do patógeno no hospedeiro, o que é atribuído a diferenças entre as células dos hospedeiros, entre outros fatores intrínsecos do patógeno e do hospedeiro (Aist, 1983). Em análise citológica da interação C. trifolii Bain \& Essary e Medicago sativa L., após a penetração do patógeno, a resposta do hospedeiro foi similar tanto para o suscetível quanto para o resistente, e se manifestou pela síntese de papilas. Porém, no material suscetível, o fungo atravessou a papila e colonizou os tecidos, enquanto que no resistente o patógeno foi retido nestas células (Mould \& Robb, 1992). A velocidade da formação da papila é um fator que pode influenciar na retenção do patógeno. Matsuoka (1988) verificou que a resistência de pimentão a Phytophthora capsici Leonian se manifesta através da rápida formação de papilas em resposta à penetração da hifa infetiva. Apesar de não ter sido feita uma avaliação quantitativa da formação de papila nos clones de guaranazeiro, a freqüência destas aparentemente não diferencia quando comparados o clone suscetível e o resistente. Desta maneira, pode-se supor que a presença de papilas não influencia na colonização dos tecidos nem na manifestação da resistência pelo clone 626 .

Diante dos resultados encontrados neste trabalho, pode-se sugerir que o clone 626 expressa sua resistência a C. guaranicola pelo atraso na entrada do patógeno e colonização dos seus tecidos, o que é uma conseqüência da baixa quantidade de formação de apressório, encontrada neste material. Segundo Pascholati \& Leite, (1995), a resistência de uma planta a um patógeno também pode ser definida como a capacidade do hospedeiro em atrasar ou evitar a entrada e subseqüente atividade de um patógeno em seus tecidos. As implicações epidemiológicas deste atraso na colonização e manifestação dos sintomas são desconhecidas para a antracnose do guaranazeiro, sendo necessários estudos adicionais envolvendo outros componentes de resistência, como período latente e severidade, a fim de avaliar o desenvolvimento da doença neste material.

\section{AGRADECIMENTOS}

À Embrapa Amazônia Ocidental, pelo fornecimento das mudas e de sua estruturas física. Ao Dr. Luadir Gasparoto, pelo auxílio e sugestões. Aos Professores, Luis A. Maffia e Murilo G. de Carvalho, pelas sugestões e correções.

\section{REFERÊNCIAS BIBLIOGRÁFICAS}

AIST, J.R. Structural reponses as resistance mechanisms. In: Bailey, J.A. \& Deverall, B.J. (Eds.). The dynamics of host defense. New York. Academic. 1983. pp.33-70.

BAILEY, J.A., O'CONNELL, R.J., PRING, R.J. \& NASH, C. Infection strategies of Colletotrichum species. In: Bailey, J.A. 
\& Jeger, M.J. (Eds.). Colletotrichum: biology, pathology and control. Wallingford. CAB International. 1992. pp.88-120.

BATISTA, M.F. Doenças do Guaranazeiro. M.A./EMBRAPAUEPAE-Manaus. Circular Técnico no 9. agosto. 1983. 27p.

BYRNE, J.M., HAUSBECK, M.K. \& HAMMERSCHIMIDT, R. Conidial germination and appressorium formatiom of Colletotrichum coccodes on tomato foliage. Plant Disease 81:715-718. 1997.

DODD, J.C., ESTRADA. A. \& JEGER, M.J. Epidemiology of Colletotrichum gloeosporioides in tropes. In: Bailey, J.A. \& Jeger, M.J. (Eds.). Colletotrichum: biology, pathology and control. Wallingford. CAB International. 1992. pp.308-325.

DUARTE, M.L.R., ALBUQUERQUE, F.C. \& CORRÊA, M.P.F. Variações morfológicas e fisiológicas em isolamentos de Colletotrichum guaranicola. Fitopatologia Brasileira 20:141144.1995.

ESQUERRÉ-TUGAYÉ, M.T., MAZAU, D., BARTHE, J.P., LAFITTE, C. \& TOUZÉ, A. Mechanisms of resistance to Colletotrichum species. In: Bailey, R.J. \& Jeger, M.J. (Eds.). Colletotrichum: biology, pathology and control. Wallingford. CAB International. 1992. pp.121-133.

GUARANÁ: aspectos agroeconômicos. Região Norte. Belém: SUDAM, 1985. p.1-22.

IBGE, Censo agrícola de 1999. http://www.sidra.ibge.gov.br

LONGO, N., NALDINI, B., DROVANDI, F., GONNELLI, T. \& TANI, G. Penetration and early colonization in basidiosporederived infection of Melampsora pulcherrima (Bub.) Maire on Mercurialis annua L. Caryologia 47:208-222. 1994.

MANANDHAR, J.B. HARTMAN, G.L. \& WANG, T.C. Anthracnose development on pepper fruits inoculated with Colletotrichum gloeosporioides. Plant Disease 79:380-383. 1995.

MATSUOKA, K. Aspectos ultra-estruturais na interação Phytophthora capsici Leonian e Capsicum annum L. (Tese de Doutorado). Viçosa. Universidade Federal de Viçosa. 1988.
MERCURE, E.W., KUNOH, H. \& NICHOLSON, R.L. Adhesion of Colletotrichum graminicola conidia to corn leaves: a requeriment for disease development. Physiological and Molecular Plant Pathology 45:407-420. 1994.

MOULD, M.J.R. \& ROBB, J. The Colletotrichum trifolii Medicago sativa interface, in culture: a cytological analysis. Canadian Journal of Botany 70:114-124. 1992.

MUNAUT, F. \& MARAITE, H. Conidium germination and appressorium penetration of Colletotrichum gloeosporioides on Stylosanthes guinensis. Journal of Phytopathology 146:1926, 1998.

O'CONNELL, R.J., URONU, A.B., WAKSMAN, G., NASH, G., KEON, J.P.R. \& BAILEY, J.A. Hemibiotrophic infection of Pisum sativum by Colletotrichum trucatum. Plant Pathology 42:774-783. 1993.

PASCHOLATI, S.F. \& LEITE, B. Hospedeiro: mecanismos de resistência. In: Bergamin Filho, A., Kimati, H. \& Amorim, L. (Eds.). Manual de Fitopatologia. São Paulo. CERES. 1995. pp.417-453.

SASS, J.E. Botanical microtechnique . $3^{\text {rd }}$ ed. Iowa. The Iowa State University. 1958.

SKIPP, R.A., BEEVER, R.E., SHARROCK, K.R., RIKKERINK, H.A. \& TEMPLETON, D. Colletotrichum. In: Komoto, K., Sinhg, U.S. \& Sinhg, R.P. (Eds.). Pathogenesis and host especificity in planta disease: histopathological, biochemical, genetic and molecular bases. New York. Pergamon. 1995. pp.119-136.

WALLER, J.M. Colletotrichum disease of perenial and other cash crops. In: Bailey, J.A. \& Jeger, M.J. (Eds.). Colletotrichum: Biology, Pathology and Control. Wallingford. CAB International. 1992. pp.167-185.

WHARTON, P.S. \& JULIAN, A.M. A cytological study of compatible and incompatible interactions between Sorghum bicolor and Colletotrichum siblineolum. New Phytologist 134:25-34. 1996. 